\title{
North-South BioDiscovery Research Collaboration of Indonesian Sponge and Soft Coral : A Bibliographic Analysis of Publications Over the Last Two Decades
}

\author{
Hedi Indra Januar \\ Department of Biotechnology, Indonesian Research and Development Center for Marine and Fisheries Products Processing and \\ Biotechnology, KS Tubun Petamburan VI Street, Slipi, Jakarta, INDONESIA.
}

\begin{abstract}
Context: The tropical Indonesian sponges and soft corals species are valuable resources that produce bioactive chemical compounds. However, BioDiscovery on those compounds requires adequate budget, modern laboratory, and skilful researchers. To foster capacity building, international collaborations with developed countries researchers have been conducted by various Indonesian institutions. In return, developed countries researchers were granted access to the tropical biodiversity resources. Aims: This study presents evaluation of Indonesian capacity development during international collaborative research on BioDiscovery of natural products from Indonesian sponges and soft corals over the last two decades. Methods and Material: Valuation had been done by bibliometric analysis, based on the authorship of Indonesian researchers in publications at major international journals on the theme of natural products BioDiscovery. Results: The study showed there were 104 publications between the year of 1994 to 2015 that reported 328 new compounds from Indonesian sponges and soft corals. Among those works, Indonesian researchers contributed as an author in $49 \%$ publications. However, the role as a principal researcher $\left(1^{\text {st }}\right.$ author) was low (14\%). Furthermore, unequal benefit sharing of research results showed, as roughly $40 \%$ of those publications did not include or acknowledge any Indonesian collaborators. All of these reflect unequal benefit sharing, and capacity of Indonesian researchers on this particular field has not been successfully developed as expected. Conclusion: The paradigm of "biodiversity data trade" and "parachute science" needs to be changed. However, it requires government support in biogenetic conservation and material transfer traceability towards equitable benefit sharing of BioDiscovery research results.
\end{abstract}

Key words: Authorship, BioDiscovery, Indonesia, Soft coral, Sponge.

\section{Key Messages}

The practices of unequal academic benefit sharing and capacity building on international BioDiscovery need to be avoided and this requires government support from both collaborators to encourage biogenetic conservation and material transfer traceability implementation, towards equitable benefits sharing of BioDiscovery research results. International North-South collaboration on marine BioDiscovery research, as it shows between developed countries and Indonesia over the last two decades, requires government support from both collaborators to encourage biogenetic conservation and material transfer traceability implementation, towards equitable benefits sharing of BioDiscovery research results.

*Address for correspondence:

Hedi Indra Januar, Department of Biotechnology, Indonesian Research and Development Center for Marine and Fisheries Products Processing and Biotechnology, KS Tubun Petamburan VI Street, Slipi, Jakarta, Indonesia.

Phone no: +62 21 5365015; Fax num: +62 2153650158

E-mail: idjanuar@kkp.go.id.

\begin{tabular}{|c|c|}
\hline \multicolumn{2}{|c|}{ Access this article online } \\
\hline Official Publication of & \\
\hline & $\begin{array}{l}\text { Website: } \\
\text { www.jscires.org }\end{array}$ \\
\hline $\begin{array}{l}\text { PhCC } \\
\text { Aringing Modichat } \\
\text { Plants Researchers }\end{array}$ & $\begin{array}{l}\text { DOI: } \\
\text { 10.5530/jscires.5.1.7 }\end{array}$ \\
\hline
\end{tabular}

\section{INTRODUCTION}

Marine sponge and soft coral are marine organisms that produce bioactive chemical compounds. A series of "Marine Natural Products"reported 7415 new chemical compounds from marine sponges and soft coralsbetween the period of 1990 and 2009. ${ }^{[1]}$ Some of these natural products are potential as a sourcesoflead compound in pharmaceutical drugs development. ${ }^{[2,3]}$ Drugs derived from marine resources already entered pharmaceutical and cosmeceutical industries, such as Prialt ${ }^{\circledR}$, Yondelis ${ }^{\circledR}$, and Carragelose ${ }^{\circledR} \cdot{ }^{[4,5]}$ However, many of prospective natural products failed in clinical phase due to efficiency 
or toxicity. Therefore, exploration into various marine organisms is needed, to gain bioactive compounds collection that can be tested in further stages.

As the needs of large marine organisms collection, this may imply Indonesia, one of thetropical coral reefhotspot with remarkable number of marine biodiversity, is one of the best areato conduct natural products-based drug discovery research. ${ }^{[6-8]}$ However, BioDiscovery research requires a modern laboratory with sophisticate instrument. Discovery of new bioactive compounds uses a streamlined "High Throughput Screening" (HTS) method by expensive chemical instruments, such as high performance chromatography, accurate mass spectrometer, and nuclear magnetic resonance. ${ }^{[9]}$ Furthermore, a team of experienced researchers is also needed, as interpretation through raw data from those chemical instruments has been a "bottleneck" step at BioDiscovery research. ${ }^{[10-12]}$ All of these factors have become the main problems for institutions or universities in Indonesia, as a developing country, to start BioDiscovery exploration on its own marine organisms. Therefore, international collaborations with developed countries researchers have been conducted by many Indonesian institutions. The collaboration aims to accelerate capacity building of Indonesian researchers. This model is called as North-South collaboration. North represents the advanced and developed countries researchers, while south represents developing countries like Indonesia. Convention on Biological Diversity (CBD) suggests developed country researchers or their organization need to share benefit and transfer technology/ knowledge in exchange for access to the biodiversity resources in developing countries. ${ }^{[13,14]}$

International collaborations have emerged to significantly increase the findings of new bioactive compounds from Indonesian marine resources. Reports of new compounds from Indonesian sponge and soft coral in 2000-2009 were increased for about 300\% compared to 1900-1999. [1] New alkaloid, terpenoid, steroid, and other types of prospective bioactive natural products werereported from Indonesian sponges and soft corals..$^{[8,15,16]}$ On the basis of these and CBD resolution, Indonesian expertise in this particular field should be in a significant progress as well, as some of the collaborations already started for about two decades ago. However up to now, there is a lack of papers that evaluate the Indonesian capacity development in marine BioDiscovery field as the impact of international collaborations. This paper presents a bibliographic analysis that aimed to examinethe possible capacity development that was gained during North-South BioDiscovery research collaboration of Indonesian sponges and soft corals over the last two decades (1994-2015). The bibliographic study was chosen as number of publications and authorship pattern in a particular field may serve as an indicator of research capability and productivity. Furthermore, on the basis of the bibliographic study, this paper also suggests a general strategy to optimize the international BioDiscovery research collaboration in the future.

\section{SUBJECTS AND METHODS}

The study was conducted through bibliographic analysis to publications on the respected journals with the theme of natural BioDiscovery products, which are Journal of American Chemistry Society, Journal of Natural Products, Bioorganic and Medicinal Chemistry, Bioorganic and Medicinal Chemistry Letters, Tetrahedron, Tetrahedron Letters, Steroids, Journal of Organic Chemistry, Natural Products Research, Marine Drugs, Asian Natural Products Research, ISRN Pharmaceutics, and Australian Journal of Chemistry. Publications were collected based on two keywords, namely "Indonesian Sponge" and "Indonesian Soft Coral" between 1994-2015 at each journal website. Authorship, acknowledgement, new compounds were reported, and description on the date of sampling activity in Indonesia had been carefully reviewed and presented by a map and bar graph, to show the trends of international collaboration results at BioDiscovery research on Indonesian sponges and soft corals over the last two decades.

\section{RESULTS}

Bibliographic analysis showed there were 175 publications of Indonesian sponges and soft corals. 104 publications of these were reported 328 new compounds from Indonesian sponges and soft corals during the period of 1994 to 2015 (Figure 1). Publications on new compound from sponge were dominant $(86 \%)$ compared to soft coral. Meanwhile, the studies had been done mostly at eastern part of Indonesia, particularly East Kalimantan, Sulawesi, Molucca, and Papua (Figure 2). Northern and Southern part of Sulawesi were the major sites at most of the publications (34\% and 20\%), as well as new compounds derived from those sites (27\% and 20\%). Bibliographic analysis showed in average; almost half of the publications were authored by Indonesian researchers (Figure 3). The contribution of Indonesian scientists was increased from the first to second decade ( $41 \%$ to $55 \%$ ). However, there are also publications that not stated any of Indonesian contributions. The number of these were decreased from the first to second decade. 


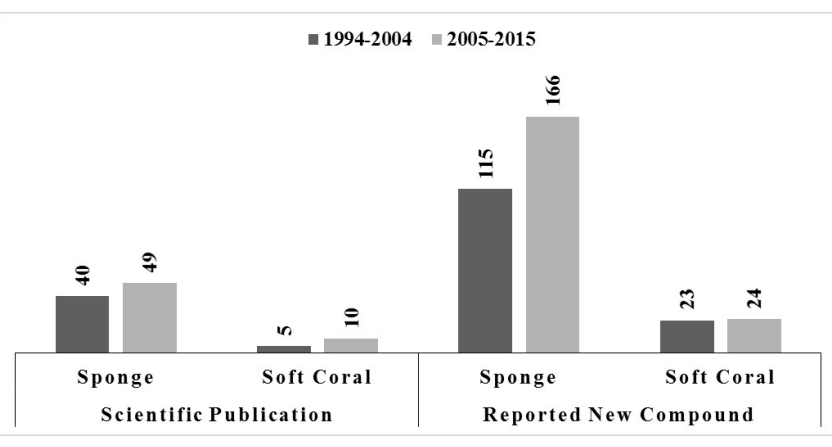

Figure 1: ???

Inspections into methodology section showed that most of the publications clearly stated the date and location of sampling activities in Indonesia (84 from 104 publications). It was also revealed $60 \%$ of publications were made during the first 5 years after sampling activities (Figure 4). Figure 4 shows that Indonesian researchers participated as an author in most of the papers published less than 10 years after the sampling activities. However, local authorship was significantly decreased in publications that being made more than 10 years after the sampling activities. Furthermore, the role of Indonesian researchers as a principal author ( $1^{\text {st }}$ author) was found to be low (Figure 5). Counterpart contributors from developed countries were appeared as principal authors in most of the publications. Meanwhile, although the percentage of principal author from Indonesian was found to be increased (2\% in 1994-2004 and 22\% in 2005-2015), there are no publications produced by Indonesian authors only.

\section{DISCUSSION}

\section{Progress of BioDiscovery Research Into Indonesian Sponges and Soft Corals}

The dominant results of new finding on chemical compounds in sponges over soft coral reflect the importance of sponge over other phyla in coral reef environment in terms of marine natural products research. As a filter feeder organism, sponge is the host of varying microorganisms. Interaction between the host and its symbiotic microorganisms may results into various chemical compounds in sponge. ${ }^{[17]}$ Therefore, sponge has been the major target of every marine natural product exploration, as it appears to be responsible for most new findings in natural products research around the world, not only in Indonesia region. ${ }^{[1]}$ Even though the results of new chemical finding in Indonesian sponges and soft coral increased significantly during two decades, its contribution is very small compared to all findings in the world in the same period. This results may suggest that explorations into natural products in Indonesia have not been optimally conducted over the last two decades.

The suggestion above arises as most of the new findings were concentrated only in two locations; the northern and southern part of Sulawesi Island. This may caused by expeditions budget, as transportation into Indonesian exotic reefs at CTI region is costly. This is a possible reason that most of collaborations had been conducted only in two areas of Sulawesi. Two largest cities at eastern

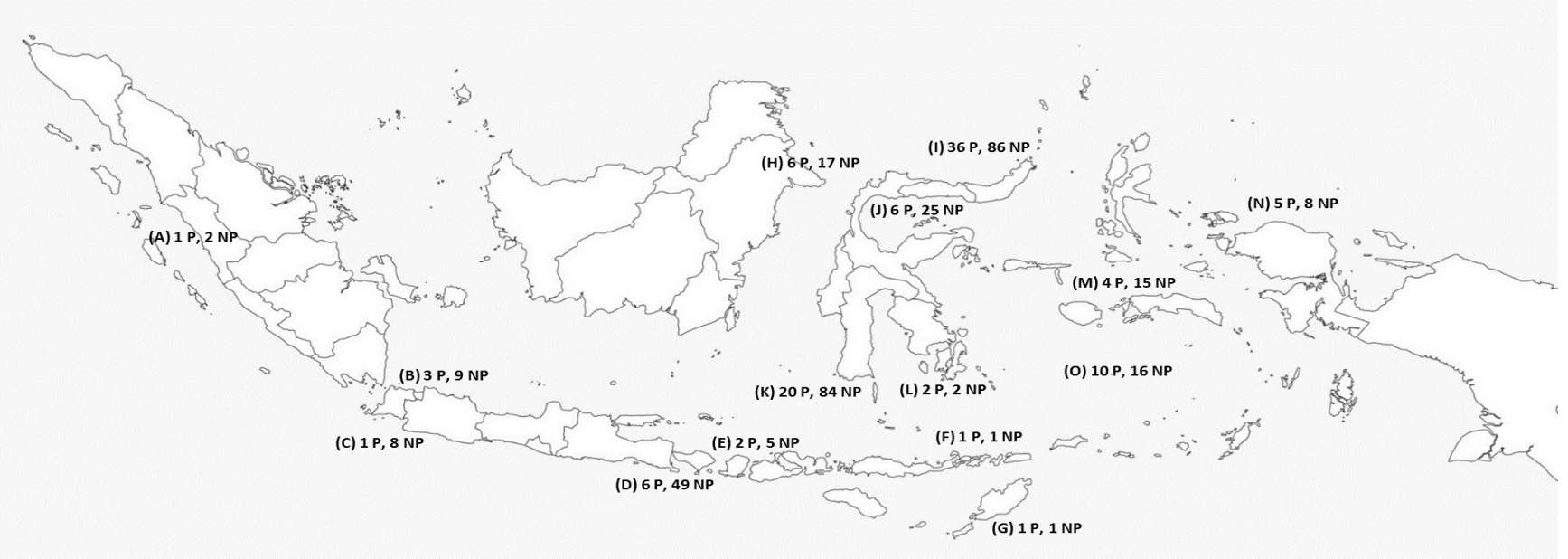

Figure 2: Location of international collaborative natural products research into Indonesian sponges and soft coral between 1994-2015, with number publications $(\mathrm{P})$ and reported new compounds $(\mathrm{NP})$ at each region $(\mathrm{A}=$ West Sumatera, B $=\mathrm{DKI}$ Jakarta, $\mathrm{C}=$ West Java, D = Bali, E = Flores Island, F = Alor, G = South East Nusa, H = East Kalimantan, I = North Sulawesi, J = Central Sulawesi, $\mathrm{K}=$ South Sulawesi, $\mathrm{L}=$ South East Sulawesi, $\mathrm{M}=$ Molucca, $\mathrm{N}=$ Papua, $\mathrm{O}=$ Undefined), and Indonesian map provided by Free Vector Maps (http://freevectormaps.com) 
past of Indonesia are within those areas, namely Manado City (Capitol of North Sulawesi Province) and Makassar City (Capitol of South Sulawesi Province). Transportation within those areas is relatively easier than most of remote reef sites around CTI Indonesian region. Moreover, there are also two respectable Indonesian universities in both

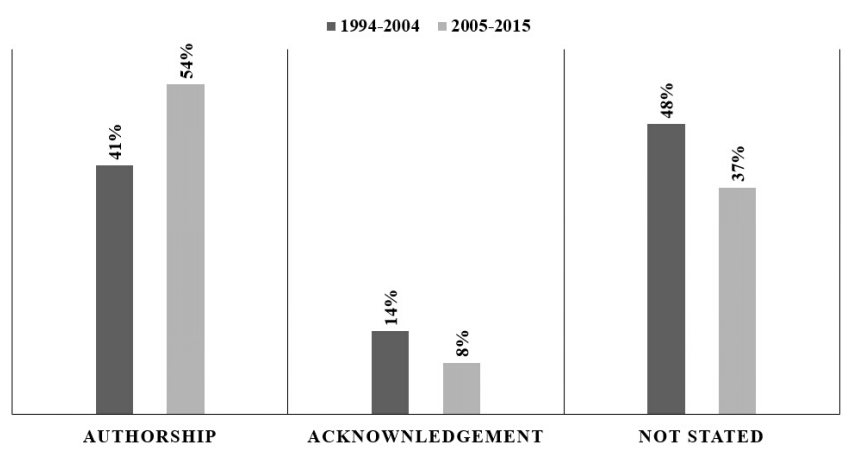

Figure 3:

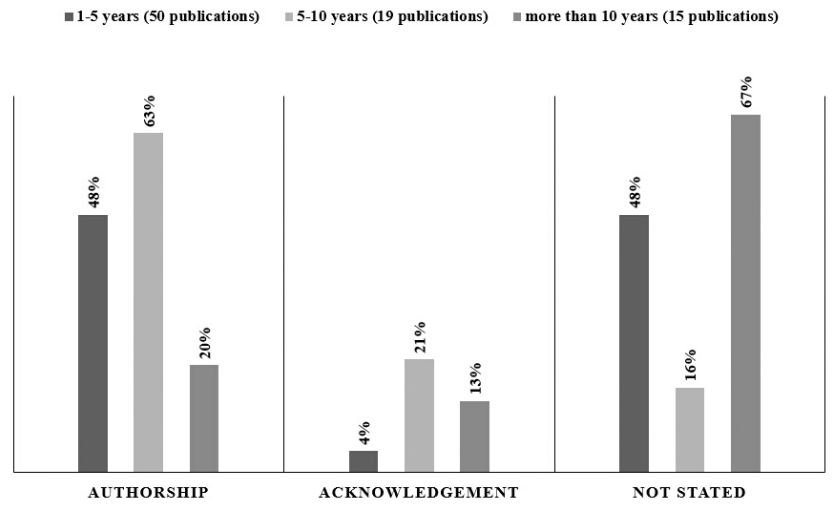

Figure 4: Percentage of Indonesian researchers contribution and duration from sampling activity to publications of biodiscovery new compounds from Indonesian sponges and soft corals between 1994 to 2015 ( $\mathrm{n}=84)$ cities: Sam Ratulangi University (Manado) and Hasanuddin University (Makassar). Researchers from both universities appeared as the major Indonesian counterparts in most of natural product publications from those regions.

\section{Authorship and Capacity Development}

The number of Indonesian researchers as a principal author is small. Even though the number was significantly increased in the second studied decade, there is no publication that was authored by all Indonesian scientists. This may indicate Indonesian researchers depended upon developed countries counterparts in all of international scientific publications on marine sponges and soft coral BioDiscovery over the last two decades. Lack of budget and modern laboratory may be accepted on the situation during 1994-2004, but in recent years, Indonesian government already invested adequate chemistry laboratory. Up to now, 6 institutes in Indonesia were already equipped with nuclear magnetic resonance and mass spectrometer; both are the most expensive instruments in BioDiscovery research. Therefore, it may suggests the dependence on developed countries scientists may come from neither the needs of budget nor advanced laboratory equipment, but from the bottleneck of local experts in this particular field. After two decades of international collaboration, the process of capacity development during international marine BioDiscovery collaboration did not happen as expected, and as a consequence, the authorship pattern showed unequal contribution at the majority of scientific publications in this particular field of research.

The pattern of inequity is commonly found in scientific collaboration between developed and developing countries researchers. In a similar case of international biodiversity research at sub-Saharan, local scientists only contributed at data collection or preliminary analysis. Furthermore,

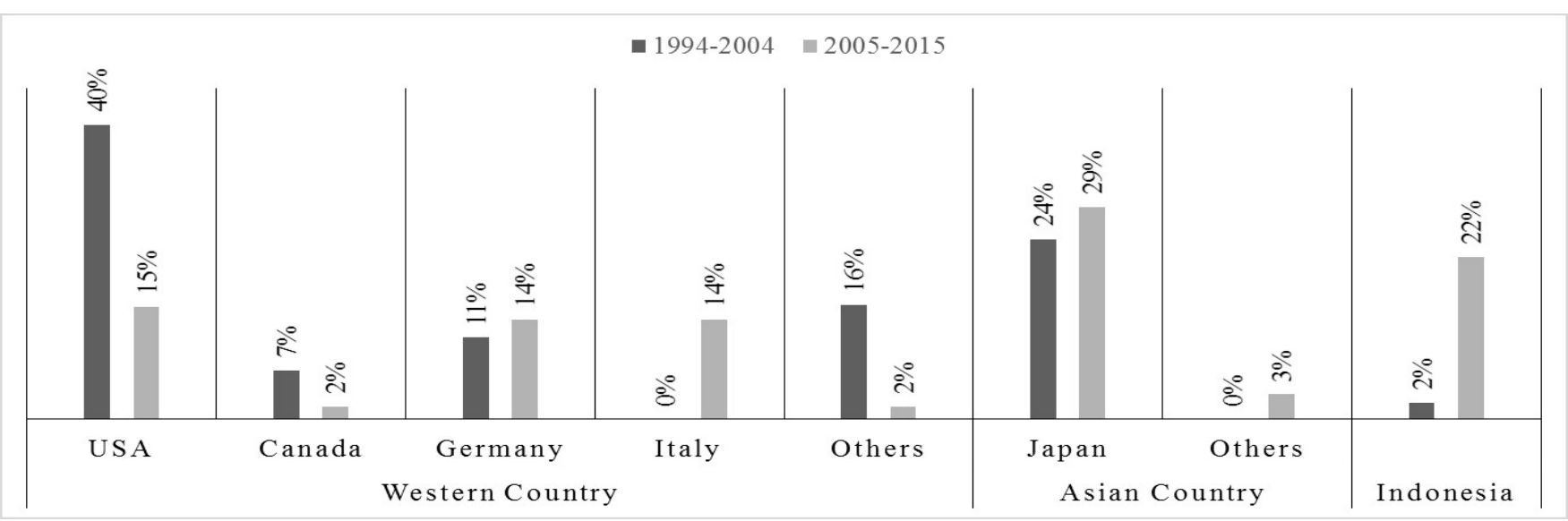

Figure 5: Percentage of principal author (1st author) in scientific publications of biodiscovery new compounds from Indonesian sponges and soft corals between 1994 to 2015 (n1994-2004 = 45 and n2005-2015 = 59) 
"biodiversity data trade" happened; the benefit gained was only at monetary profits as local institutes often asked for financial input when acting as a local counterpart. ${ }^{[18]}$ Moreover, there were frequent cases of local contributor inferiority and lack of motivation to develop themselves into international sciences. Monetary benefit during sampling activities and systems in Indonesia give strong incentives to advanced careers if contributing as an author in international journals; this leads to the common honorary authorship for local Indonesian contributors. ${ }^{[19]}$ Meanwhile, developed countries researchers usually participate in larger portion into budget or expenditures at field-research activities. This situation, combined with local contributors inferiority on bargaining position, frequently leads to superiority of developed counties researchers in a decision making on the biomaterial derived from sampling activities. It is common that developed countries researchers work by "parachute science"; a developing country is only a place for data collection or preliminary research, and further study takes place in a developed country as they bring the samples to their home base laboratory. ${ }^{[19]}$ In several cases, this practice is done without proper biological material transfer agreement. Low enforcement in biological material conservation in developing countries also contributes to "parachute science" practice. This may leads to the lack of trust to foreign researchers, as they are viewed as exploitative "bio-colonialism" by developing countries governments and researchers. ${ }^{[20]}$

\section{Addressing the "Biodiversity Data Trade" and "Parachute Science"}

The impact of "biodiversity data trade" and "parachute science" was obvious as approximately $40 \%$ of new chemical compound findings during 1994-2015 did not state any Indonesian contributions. Publications that not stated any of Indonesian contributions were increased after 10 years of sampling activities. This may suggests that there are plenty of Indonesian sponges and soft corals biomaterials that have been deposited in developed countries laboratories. When there are new methods or bioactivity targets, developed countries researchers can re-analysis those samples without the needs of Indonesian counterpart anymore. This bibliographic study found a publication in 2014 about new chemical finding on sponge that was taken 22 years ago from Indonesian region and without any acknowledgement to Indonesian collaborators.

Both contributors need to change the relationship mindset in international BioDiscovery research. Integration of research collaboration and capacity development needs to be enhanced by mutual respect on research ethics, integrity, biogenetic conservation, and material transfer traceability on the basis of CBD resolution. ${ }^{[19]}$ This study suggests two methods that should be applied simultaneously. First, to address "biodiversity data trade", local contributors need to enhance their motivation on sciences rather than monetary profit. Inferiority of local parties and superiority of foreign contributors need to be avoided as both equally require each other. Developing countries researchers need to develop their capacity in BioDiscovery field as the basis for biodiversity conservation on their own region and developed countries researchers need an access to apply their advanced science. Mutual respect and trust may lead to long term collaboration that will be a benefit to both parties. Secondly, the practice of "parachute science" should also be avoided. Indeed in the past, the needs to bring the samples into developed countries laboratory constrain "the realization" of greater benefits for all parties in collaborative research. ${ }^{[19]}$ However, as some of Indonesia institutes are already equipped with sophisticated instruments, the paradigm needs to be changed; the bottleneck is not in budget or research instruments but in fostering the science expertise in Indonesia.

\section{REFERENCES}

1. Leal MC, Puga J, Serôdio J, Gomes NCM, Calado R. Trends in the discovery of new marine natural products from invertebrates over the last two decades-where and what are we bioprospecting?. PloS One. 2012;7(1):p.e30580.

2. Harvey AL. Natural products in drug discovery. Drug Discov Today. 2008;13(19):894-901.

3. Kiuru P, D'Auria MV, Muller CD, Tammela P, Vuorela $H$, Yli-Kauhaluoma J. Exploring marine resources for bioactive compounds. Planta Med. 2014;80(14):1234-46.

4. Schuster $D$, Laggner $C$, Langer $T$. Why drugs fail-A study on side effects in new chemical entities. Curr Pharm Des. 2005;11(27):3545-59.

5. Martins A, Vieira H, Gaspar H, Santos S. Marketed Marine Natural Products in the Pharmaceutical and Cosmeceutical Industries: Tips for Success. Mar Drugs. 2014;12(2):1066-101.

6. Allen GR. Conservation hot spots of biodiversity and endemism for Indo-Pacific coral reef fishes. Aquat Conserv. 2008;18(5):541-56.

7. de Voogd NJ, Becking LE, Cleary DF. Sponge community composition in the Derawan islands, NE Kalimantan, Indonesia. Mar Ecol Prog Ser. 2009;396:169-80.

8. Chasanah E. Marine BioDiscovery research in Indonesia: challenges and rewards. J Coastal Dev. 2008;12(1):1-12.

9. Januar HI, Ariyanto D, Muhaemin M, Kusumawati PJ, Putranto $\mathrm{S}$. Method and application of high throughput screening into exploration of BioDiscovery on bioprospecting compounds from marine sponge and soft coral. Indonesian J Omni-Akuatika. 2015;XIV:23-32.

10. Jaspars M. Computer assisted structure elucidation of natural products using two-dimensional NMR spectroscopy. Nat Prod Rep. 1999;16(2):241-8. 
11. Aguilar JA, Cassani J, Delbianco M, Adams RW, Nilsson M, Morris GA. Minimizing Research Bottlenecks by Decluttering NMR Spectra. Chem Eur J.2015;21(17):6623-30.

12. Vaniya A,Fiehn $O$. Using fragmentation trees and mass spectral trees for identifying unknown compounds in metabolomics. Trends Analyt Chem. 2015;69: 52-61.

13. Artuso A. Bioprospecting, benefit sharing, and biotechnological capacity building. World Dev. 2002;30(8):1355-68.

14. Kingston DGI. Modern Natural Products Drug Discovery and its Relevance to Biodiversity Conservation. J Nat Prod. 2011;74(3):496-511.

15. Putra MY, Jaswir I. The Alkaloids from Indonesian Marine Sponges, Oceanogr. 2014;2:4172/2332-2632.1000125.

16. Tapilatu YH. Status of Drug Discovery Research Based on Marine Organisms from Eastern Indonesia. Procedia Chem. 2015;14:484-92.
17. Uria A, Piel J. Cultivation-independent approaches to investigate the chemistry of marine symbiotic bacteria. Phytochem Rev. 2009;8(2):401-14.

18. Habel JC, Eggermont H, Günter S, Mulwa RK, Rieckmann M, Koh LP, et al. Towards more equal footing in north-south biodiversity research: European and sub-Saharan viewpoints. Biodivers Conserv. 2014;23(12):3143-8.

19. Barber PH, Ablan-Lagman MCA, Berlinck RGS, Cahyani D, Crandall ED, Ravago-Gotanco R, et al. Advancing biodiversity research in developing countries: the need for changing paradigms. Bull Mar Sci. 2014;90(1):187-210.

20. Boshoff N. Neo-colonialism and research collaboration in Central Africa. Scientometrics. 2009;81(2):413-34. 